\title{
Quantifying Risk in the Electricity Business: A RAROC-based Approach
}

\author{
Marcel Prokopczuk ${ }^{a}$, Svetlozar T. Racheva,b,2, \\ Gero Schindlmayr ${ }^{\mathrm{c}}$ and Stefan Trück ${ }^{\mathrm{a}, 1}$ \\ ${ }^{a}$ Institut für Statistik und Mathematische Wirtschaftstheorie, Universität \\ Karlsruhe, Kollegium am Schloss, D-76128 Karlsruhe, Germany \\ ${ }^{\mathrm{b}}$ Department of Statistics and Applied Probability, University of California, Santa \\ Barbara, CA 93106, USA \\ ${ }^{\mathrm{c}}$ EnBW Trading GmbH, Durlacher Allee 93, D-76131 Karlsruhe, Germany
}

\begin{abstract}
The liberalization of electricity markets has forced energy producing companies and traders to calculate costs closer to the profit frontier. Thus, an efficient risk management and risk controlling are needed to ensure the financial survival even during bad times. Using the RAROC methodology we provide a new framework to quantify risks related to wholesale electricity contracts, also called full load contracts. We do not only consider risk of market price fluctuations but also correlation effects between the spot market price and the load curve of a customer. We further conduct an empirical study on whole sale contracts for industry customers and public utility companies of a German energy provider. Our findings support the adequateness of the approach and point out the importance of considering also price-volume correlation effects for electricity whole sale contracts.
\end{abstract}

Key words: Power Markets, Spot Market Prices, Load Contracts, Risk Management, RAROC

$\overline{1}$ Corresponding Author, email: stefan@statistik.uni-karlsruhe.de.

2 Rachev gratefully acknowledge research support by grants from Division of Mathematical, Life and Physical Sciences, College of Letters and Science, University of California, Santa Barbara, the Deutschen Forschungsgemeinschaft and the Deutscher Akademischer Austausch Dienst. 


\section{Introduction}

In the last decade electricity markets have been transformed from a primarily technical business, to one in which products are treated in much the same way as any other commodity. The liberalization led to a radical change in the structure of power markets all over the world. Energy exchanges have been established as competitive wholesale markets where electricity spot prices as well as future contracts are traded.

As a consequence of the switch from virtually fixed and regulated prices to the introduction of competitive pricing, both consumers as producers are exposed to significantly greater risks (Kaminski, 1999). As pointed out by Pilipovic (1997) electricity shows a unique and extremely volatile behavior of spot prices. From an economic viewpoint electricity is non-storable, which causes demand and supply to be balanced on a knife-edge. End user demand shows strong seasonality and relatively small changes in load or generation can cause large changes in prices and all in a matter of hours or even minutes (Clewlow and Strickland, 2000; Lucia and Schwartz, 2002; Weron, 2000).

Due to the riskiness in electricity prices even for large companies and public utility companies (PUC) the exchange itself is not the main distribution channel. Energy trading companies were established, which act as intermediate between the power generating and the sales businesses, as well as with the outside market. Many industrial customers do not want to bother to buy electricity at an exchange due to the risk of highly volatile prices. They rather make direct contracts with the electricity company or a trader to provide them with as much electricity as they need for a fixed price per unit. Entering such a contract, also called full load contract, the electricity trader commits himself to deliver an unknown amount of electricity for a fixed price per unit. Due to extreme price variations, in the past, energy traders faced large losses or even defaulted on wholesale electricity contracts (EIA, 1999). This means the trader is willing to bear several kinds of risks in place of the customer, for which she should be compensated by a risk premium. However, to remain competitive, prices have to be calculated often rather close to profit frontiers. The calculation should also consider risk management aspects to ensure the financial survival of the trader even in case of bad market scenarios. Hence, the premium should be calculated according to the customers profile, the market risk of electricity spot prices and some performance measure embodying the demanded risk-adjusted return of the trading company. Adequate measures for evaluation of the latter could be e.g. Value-at-Risk (Jorion, 2001), expected shortfall (Artzner et al., 1999) or also the RAROC approach (Punjabi, 1998).

The aim of the paper is twofold. We provide a new approach to quantifying the risk for an energy provider related to full load contracts using the RAROC 
methodology. Based on our model, accounting for market price risk, volume risk and correlations between these risk factors adequate risk premiums for a customer can be determined. Besides, our framework enables the energy provider to distinguish between customers according to their load profiles, a main determinant of the riskiness of the contract. This can be considered as a useful tool for hedging purposes and optimization of a load contract portfolio.

The remainder of the paper is set up as follows. Section 2 gives an introduction to risk-adjusted performance measures and the RAROC framework. Section 3 develops a model for energy RAROC with deterministic and stochastic load. The section also illustrates how energetic hedges by using future contracts can be included. In section 4 we determine risk premiums for full load contracts based on market price risk, volume risk and correlations between these risk factors. Section 5 concludes and makes some suggestions for future work.

\section{The RAROC Framework}

\subsection{Performance Measures}

The traditional performance measures to evaluate the performance of a company, business unit or single investment are mainly RoI - Return on Investment and RoE - Return on Equity. RoI compares the return to the amount of invested money, where RoE only takes the invested equity capital into account. The shortcomings of these concepts are obvious: They are accounting-based and do not reflect the real performance of an investment. Neither do they take into account the risk of the investment nor is it possible to determine the invested capital for single business units from the firm's balance sheet.

The need to compare the performance of portfolios and business units with respect to their risk has been addressed by many authors. Based on the portfolio and capital market theory several measures have been developed, among them Jensen's Alpha, Jensen (1968), the Treynor Index, Treynor (1965) and the Sharpe Ratio, Sharpe (1966).

Jensens Alpha measures the difference between the actual rate of excess return and the theoretical one given by the Capital Asset Pricing Model. Thus, it measures the performance of the portfolio compared to the market and makes it possible to compare two portfolio managers. But since it takes only into account the systematic risk, the comparison is only fair if two portfolios have the same systematic risk, which is not true in general. The Treynor index, also called reward-to-volatility-ratio, measures the excess return adjusted by the systematic risk. Thus it is subject to the same criticism as Jensens Alpha. 
The reward-to-variability-ratio of Sharpe is similar to the Treynor index but adjusts the excess return with the overall risk, measured by the standard deviation of the portfolio. The Sharpe Ratio has the advantage that it takes also unsystematic risk into account.

The general problem of these measures is that they lead to dimensionless numbers, which are well suited to compare single portfolios, but do not enable the management to control the overall risk of the firm. Furthermore Jensens Alpha and the Treynor Ratio are based on the CAPM and thus are also subject to the criticism of it. The Sharpe Ratio overcomes these deficiencies but from a risk management point of view the standard deviation does not seem to be the appropriate risk measure. Risk management aims to protect the company from heavy downward movements, i.e. big losses, but the standard deviation is also sensitive to upward movements.

In the need of an efficient risk management and the ability to compare different business units new Risk Adjusted Performance Measures (RAPMs) have become popular in the banking business. Many acronyms for RAPMs can be found in the literature, e.g. Risk adjusted Return on Capital (RAROC), Punjabi (1998); Jorion (2001), Return on Risk adjusted Capital (RORAC), Punjabi and Dunsche (1998); Lehar et al. (1998), Risk adjusted Return on Risk adjusted Capital (RARORAC), Punjabi and Dunsche (1998). This can be very confusing, especially because same acronyms can stand for different things and equal things sometimes have different names.

We follow the most prominent definition in the literature and define $R A R O C$ as:

$$
R A R O C=\frac{\text { Expected Return }}{\text { Economic Capital }}
$$

The Economic Capital (EC) is the amount of money needed to secure the banks survival in a worst case scenario, i.e. it is a buffer against heavy shocks. It should capture all types of risk (market, credit and operational risk) and is often calculated by the Value at Risk $(\mathrm{VaR})^{3}$. The VaR is a quantile of the profit and loss (P\&L) distribution, i.e. it measures the maximum amount of money one can lose at a given confidence level in a specified period of time. If $X$ is the random variable describing the profit and loss of the business, the formula to compute VaR at a level of $\alpha$ is:

$$
P(X<-V a R)=\alpha
$$

If we express the Economic Capital as VaR, (1) becomes:

$\overline{3}$ For details see Jorion (2001) 


$$
R A R O C=\frac{\text { Expected Return }}{\text { VaR }}
$$

The appealing thing about RAROC is that it provides a uniform measure of performance that the management can use to compare businesses with different sources of risk and capital requirements, Zaik et al. (1996). Hence, RAROC is not only suited to compare all kinds of businesses with each other, it is also a powerful management tool for capital allocation and risk control.

Based on RAROC we are able to make a well funded decision about different investment alternatives in terms of return-risk tradeoff. However a high RAROC does not necessarily mean that the investment is also profitable. Since the ultimate goal of a company is to increase its Shareholder Value, the decision rule in a RAROC-based framework should be:

$$
\text { Invest in project } \mathrm{A} \Longleftrightarrow \mathrm{RAROC}(\mathrm{A})>\mu
$$

where $\mu$ is the internal hurdle rate reflecting the cost of equity capital. Determining the Cost of Equity Capital is not easy and there can be found several approaches to this problem. A common way among practitioners is to take the expected return of the shareholders as hurdle rate. Another popular possibility is to use the expected return determined by the CAPM. Theoretically more advanced approaches can be found in Froot and Stein (1998) or Galai and Masulis (1976).

\section{A Model for an Energy-RAROC}

In the sequel we develop a model to calculate the RAROC of an electricity contract. We start with a discussion of an appropriate risk measure for our situation. Then we formulate the RAROC equation assuming a deterministic customer load. This assumption is relaxed afterwards where we also allow for stochastic load paths of individual customers. In the end of the section we show how part of the risk can be hedged, using future markets to reduce the risky exposure.

\subsection{The appropriate Risk Measure: VaR or CFaR?}

As described above, the Economic Capital is usually calculated as VaR. However, in our case, VaR cannot be considered as an appropriate measure of risk, since VaR implicitly assumes the possibility to close the risky position at any 
time on the future or forward market. In the energy business this assumption is not justified because the illiquidity of the market. Hourly products can only be traded on the spot market (or OTC) and monthly contracts go only half a year ahead. Furthermore the amount of energy traded on the future market is also very limited.

Thus, in our analysis we will use a similar but slightly different measure - the Cash Flow at Risk (CFaR). The difference to VaR is that we do not assume it is possible to close ones position at any time, but we have to wait until the maturity day is reached. Having no electricity production, we have to buy the electricity at the spot market. Here the difference between VaR and CFaR becomes obvious: VaR is based on the future prices, $\mathrm{CFaR}$ on the spot prices. Since there is no future market for products with a granularity of hours and the OTC market for those products is not liquid, the usage of CFaR makes more sense when dealing with full load contracts.

\subsection{RAROC with deterministic Load}

We will now develop a model to calculate RAROC for the electricity business with hourly granularity. Let us therefore assume the situation from the viewpoint of an electricity trader who neither has any own facilities to produce electricity nor any usage for it.

We further assume to have a customer who wants to buy electricity for a fixed amount of money per unit. Furthermore, in our first step we assume that the customers' demand load is fixed and known, i.e. deterministic. We will relax this assumption in the next section and extend the model for stochastic load demand.

Recall the original RAROC equation:

$$
R A R O C=\frac{\text { Expected Return }}{\text { Economic Capital }}
$$

where we want to explain how the numerator and the denominator of this fraction can be determined.

Let us first determine the numerator. The expected return can be calculated as the expected value of the cash flows in the future. Assume, we agreed to deliver energy for one year to our customer for a fixed retail price $K$, his (deterministic) load curve is $\hat{l}_{t}$ and the (stochastic) future spot price of one MWh at time $t$ is $S_{t}$. Then the profit for the trader ${ }^{4}$ of each hour is the difference

$\overline{4}$ Note that profit could also include negative profits, i.e. losses. 
between the retail and the spot price per MWh times the amount of energy. This is the future cash-flow in hour $t C F_{t}$. Since $S_{t}$ is stochastic, this is also the case for $C F_{t}$ :

$$
\mathbb{E}\left[C F_{t}\right]=\mathbb{E}\left[\left(K-S_{t}\right) \hat{l}_{t}\right]=K \hat{l}_{t}-\mathbb{E}\left[S_{t}\right] \hat{l}_{t}
$$

To get the entire profit we just have to sum over all hours from the starting date $\tau$ of the contract until the end date $\mathrm{T}$ and discount the cash flows to the actual point in time, which we denote with $t_{0}$.

For simplicity we assume a constant interest rate $r$ with continuous compounding since the impact of the interest rate is not the core point of our analysis. We point out that also the hourly compounding is a simplification since payments are not done hourly in the real business world. For example, contracts at the EEX are settled daily, direct retail contracts with customers are usually settled monthly. Since payments dates differ among customers one would have to evaluate each contract differently. With this assumption we get the following equation for the profit:

$$
\mathbb{E}[\text { Profit }]=\mathbb{E}\left[\sum_{t=\tau}^{T} B_{0}(t) C F_{t}\right]=\sum_{t=\tau}^{T} B_{0}(t) \mathbb{E}\left[\left(K-S_{t}\right) \hat{l}_{t}\right]
$$

With $B_{0}(t)=\exp \left(-\int_{0}^{t} r(u) d u\right)$ denoting the discount function. Thus, for each price path we can calculate the profit (i.e. the sum of all cash flows) and our best estimate for the expected profit is the mean of all profit realizations.

As described in the previous section, the Economic Capital should be the amount of money we can lose in a worst case scenario. We want to ensure that even under a very bad development we will still have enough capital to ensure the survival of the company. Therefore the Economic Capital should be invested in a risk free asset, e.g. US or German government bonds, to cover unexpected losses. For CFaR, following Dowd (1998) we decided to use the so-called relative $C F a R_{\alpha}$, which is defined as the difference between the mean and the $\alpha$-quantile of the profit and loss distribution. Thus, the RAROC of an energy project with a deterministic load profile becomes:

$$
R A R O C=\frac{\sum_{t=\tau}^{T} B_{0}(t) \mathbb{E}\left[\left(K-S_{t}\right) \hat{l}_{t}\right]}{\sum_{t=\tau}^{T} B_{0}(t) \mathbb{E}\left[\left(K-S_{t}\right) \hat{l}_{t}\right]-q_{\alpha}\left[\sum_{t=\tau}^{T} B_{0}(t)\left(K-S_{t}\right) \hat{l}_{t}\right]}
$$


where $q_{\alpha}$ denotes the $\alpha$-quantile.

\subsection{RAROC with stochastic load}

We will now extend the framework to stochastic load profiles. Generally, the load process of a full load contract customer is not deterministic. We do not know the future load process, however one might be able to estimate the load curve with the help of historical data. This estimation could then be used to compute an ex-ante RAROC as described in the previous section.

Deviations from the estimated load curve $\hat{l}_{t}$ can have various reasons. Similar to the concepts known from modern capital market theory, in the following we will distinguish between systematic and unsystematic reasons.

Unsystematic reasons are caused by specific incidents at the customer and do not have their source in the market (e.g. a malfunction of a big machine, short-term variation in production activities, etc.). Systematic reasons, on the other hand, originate from variation in the market which have an impact on all customers (e.g. a cold snap).

Written as formula this means for the load $l_{i}$ of customer i:

$$
l_{i}=\hat{l}_{i}+\beta_{i} \varepsilon_{\text {syst }}+\varepsilon_{i}
$$

where $\varepsilon_{\text {syst }}$ is the systematic risk of the market, $\beta_{i}$ describing the intensity of correlation between the customer and the systematic risk. Further, $\varepsilon_{i}$ is the unsystematic risk of customer $i$. Note that by definition the unsystematic risk is only related to the customer himself, there is no connection to other customers, i.e. for any two customers $i$ and $j$ :

$$
\operatorname{Cov}\left(\varepsilon_{i}, \varepsilon_{j}\right)=0
$$

Furthermore, we assume the unsystematic risk of each customer $i$ to be uncorrelated with the systematic risk, i.e.:

$$
\operatorname{Cov}\left(\varepsilon_{i}, \varepsilon_{\text {syst }}\right)=0
$$

Note that an electricity trader with a big portfolio of customers can be regarded as well diversified. That means the risk of variations due to unsystematic reasons (unsystematic risk) of all customers together can be assumed to compensate each other in average. Hence, the remaining risk factor is the 
variation due to systematic reasons (systematic risk), which can be explained by variation in the entire grid load.

Now let the entire grid load process be $L_{t}$ and let further $\hat{L}_{t}$ be the deterministic grid load forecast based on some spot price model with $24 \mathrm{~h}$ seasonality.

To use the grid load process for generating simulations for the customer's load process we will first have to estimate the customer's correlation with the entire grid load. We estimate the impact of fluctuations of the grid load on the customer load by a linear regression model. Precisely we determine the portion of deviation of the customer load from the estimated load which can be explained by the deviation of the grid load from the estimated grid load. Hence, we set

$$
\tilde{l}_{t}=\frac{l_{t}-\hat{l}_{t}}{\hat{l}_{t}}
$$

and

$$
\tilde{L}_{t}=\frac{L_{t}-\hat{L}_{t}}{\hat{L}_{t}} .
$$

Then our regression model can be written as:

$$
\tilde{l}_{t}=\beta \cdot \tilde{L}_{t}+\varepsilon_{t}
$$

where

$l_{t}=$ actual customer load

$\hat{l}_{t}=$ estimated customer load

$L_{t}=$ actual entire grid load

$\hat{L}_{t}=$ estimated entire grid load

$\beta=$ regression coefficient

$\varepsilon_{t}=$ error term (unsystematic risk)

The value of $\beta$ can be estimated using standard OLS.

Thus, we get for $\hat{\beta}$ :

$$
\hat{\beta}=\frac{\operatorname{Cov}\left(\tilde{l}_{t}, \tilde{L}_{t}\right)}{\operatorname{Var}\left(\tilde{L}_{t}\right)}
$$

To compute a customer's beta we need $\tilde{L}_{t}$ and $\tilde{l}_{t}$, the deviations of grid and customer load. For the estimation historical load data of the customer can be used. We further build a class for each weekday. Tuesday, Wednesday and 
Thursday are put together into one class since the load curves of them are historically very similar. We do this classification for each month and additionally we distinguish holidays. Our best estimate of a customers load at point $t$ is the average of all observation being in the same class as t. Having the load estimation an the true realization we can compute $\tilde{l}_{t}$ and thus the $\beta$ for each customer.

Equipped with these betas we can generate stochastic load paths depending on the systematic risk of each individual customer. For this we generate grid load paths for $L_{t}$ and compute the relative deviation $\lambda_{t}$ from the mean $\hat{L}_{t}$ for each path $L_{t}^{i}$, i.e.:

$$
\lambda_{t}^{i}=\frac{L_{t}^{i}-\hat{L}_{t}}{\hat{L}_{t}}
$$

Having done this for each hour and each path we can now generate $i$ different load paths for the customer load by multiplying the estimated load path $\hat{l}_{t}$ with $\beta \lambda_{t}^{i}$ and adding this deviation to the estimated load $\hat{l}_{t}$ :

$$
l_{t}^{i}=\hat{l}_{t}+\hat{l}_{t} \cdot \beta \cdot \lambda_{t}^{i}
$$

The profit function is now depending on two sources of uncertainty: The spot prices and the customer load curve. The expected value is given by:

$$
\mathbb{E}[\text { Profit }]=\sum_{t=\tau}^{T} B_{0}(t)\left(K \mathbb{E}\left[l_{t}\right]-\mathbb{E}\left[S_{t}\right] \mathbb{E}\left[l_{t}\right]-\operatorname{Cov}\left(S_{t}, l_{t}\right)\right)
$$

Here, we see that in order to evaluate the expected value of the profit, we even do not need to generate simulations for the customer load. Having the simulated grid load paths is sufficient, since $\mathbb{E}\left[l_{t}\right]=\hat{l}_{t}$ and using (14), (18) becomes:

$$
\mathbb{E}[\text { Profit }]=K \sum_{t=\tau}^{T} B_{0}(t) \hat{l}_{t}-\sum_{t=\tau}^{T} B_{0}(t) \mathbb{E}\left[S_{t}\right] \hat{l}_{t}-\sum_{t=\tau}^{T} B_{0}(t) \hat{l}_{t} \beta \operatorname{Cov}\left(\tilde{L}_{t}, S_{t}\right)
$$

As we will see later, this result is helpful when we want to compute the covariance between the spot price $S_{t}$ and a customer load $l_{t}$. Unfortunately if we want to compute a contract's RAROC we still need to generate load paths for the customer because not only the mean but also the $\alpha$-quantile enters the calculation. 


\subsection{RAROC with the possibility of Hedging}

In the previous section we did not consider the possibility to hedge a part of the risk on the future market. However, in most countries there is also a market for future contracts. In Germany, for example, futures are traded on the EEX or by various brokers. We point out that our justification to use CFaR instead of VaR still holds, since there are only monthly, quarterly and yearly future contracts available. Nevertheless we want to calculate RAROC on an hourly basis. Thus, it is only possible to hedge some of the risk but not all of it. On the EEX two different products can be used for hedging: baseload and peakload future contracts. A baseload contract means the constant delivery of $1 \mathrm{MW}$ $24 \mathrm{~h}$ hours a day, seven days a week while a peakload contract includes the delivery of $1 \mathrm{MW}$ from 8:00am to 8:00pm Monday through Friday (including holidays).

Still the question remains which hedging strategy to follow. One intuitive (and physically meaningful) solution to this problem is to follow a so-called energetic hedge strategy. This means we buy a future on the same amount of total energy we are going to sell to our customer. When dealing with stochastic load paths, we take the average values to compute the sum of energy.

Let $\eta=\left(\eta_{\text {base }}, \eta_{\text {peak }}\right)$ denote the energetic hedge strategy where $\eta_{\text {base }}$ and $\eta_{\text {peak }}$ denote the number of baseload and peakload contracts bought or sold, respectively. This strategy can be calculated by:

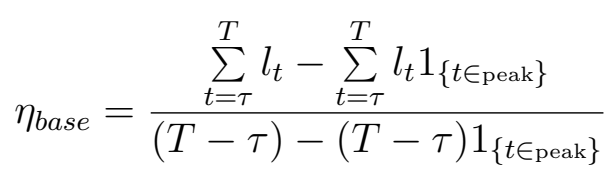

and

$$
\eta_{\text {peak }}=\frac{\sum_{t=\tau}^{T} l_{t} 1_{\{t \in \text { peak }}}{}(T-\tau) 1_{\{t \in \text { peak }\}}-\eta_{\text {base }}
$$

where $1_{\{t \in \text { peak }\}}$ denotes the indicator function, i.e.:

$$
1_{\{t \in \text { peak }\}}=\left\{\begin{array}{l}
1, \text { if } \mathrm{t} \text { is a Peakhour } \\
0, \text { else }
\end{array}\right.
$$

Figure 1 shows an exemplary loadcurve of a customer and the energetic hedge position for it. As we are short in the load and long in the hedge position, only the difference remains as risky position. This new load curve is shown in figure 2. A negative load means that we are going to sell the energy at the exchange. If $\pi_{\text {peak }}$ and $\pi_{\text {base }}$ denote the prices of peakload and baseload future 


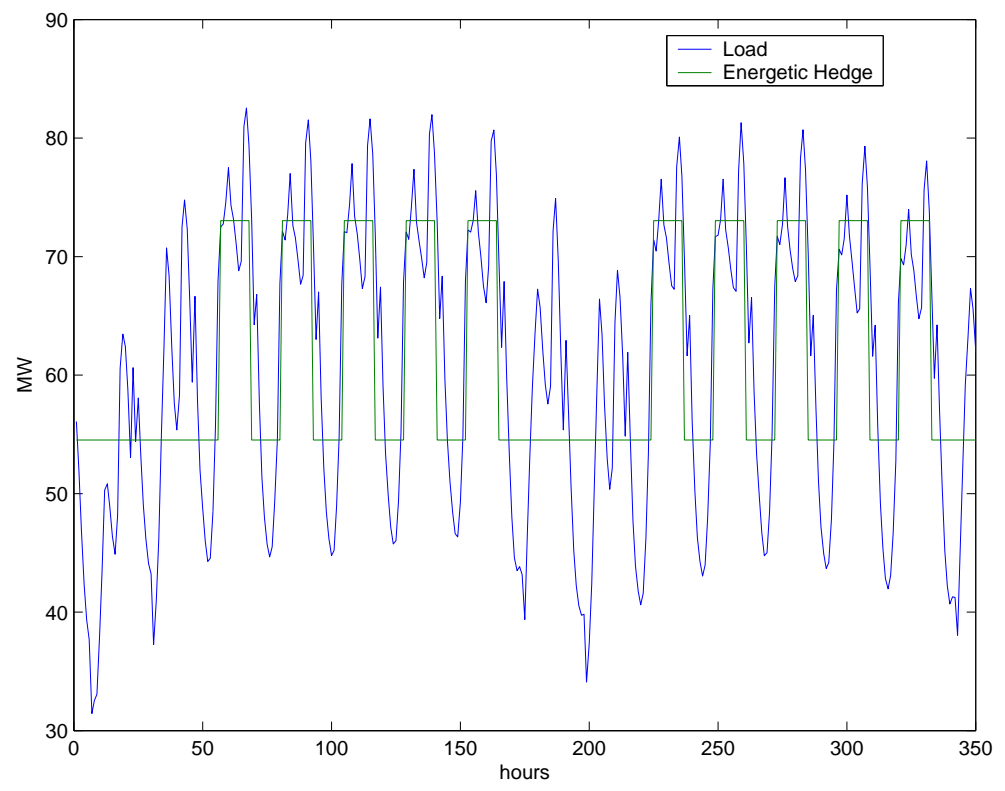

Fig. 1. Energetic Hedge for a typical customer load

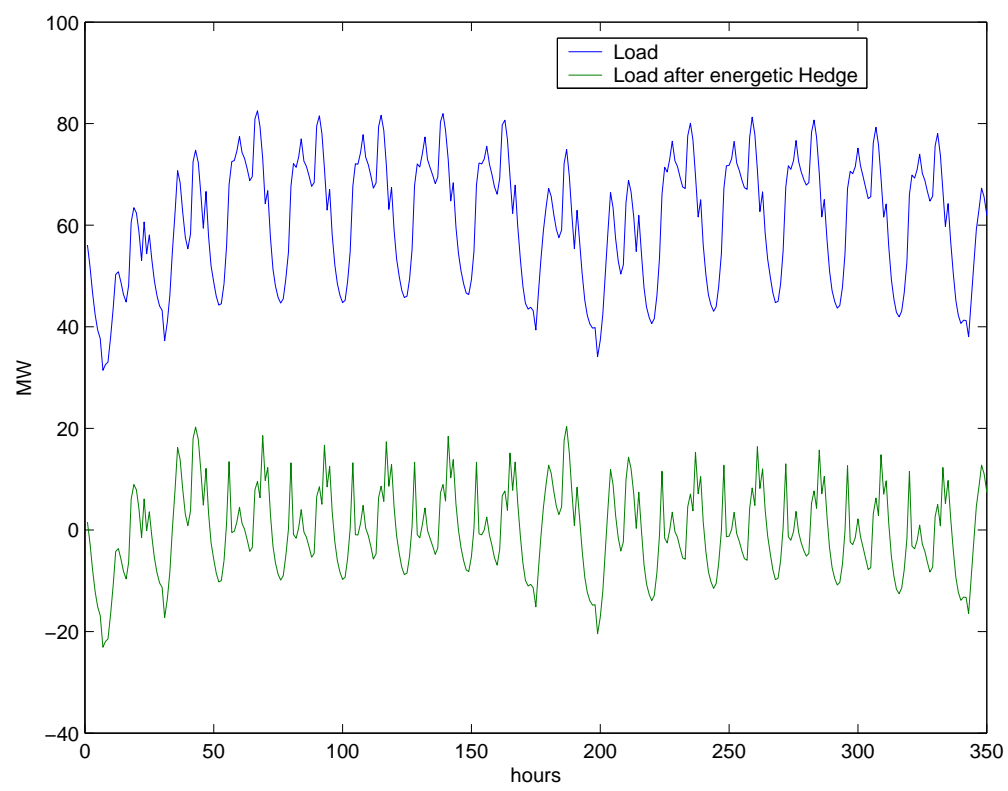

Fig. 2. Load after entering an energetic hedge position contracts, the profit and loss function becomes:

$$
\begin{aligned}
\text { Profit }= & K \sum_{t=\tau}^{T} B_{0}(t) l_{t}-\sum_{t=\tau}^{T} B_{0}(t)\left(\eta_{\text {base }} \pi_{\text {base }}+\eta_{\text {peak }} \pi_{\text {peak }} 1_{\{t \in \text { peak }\}}\right) \\
& \left.+\sum_{t=\tau}^{T} B_{0}(t)\left(\left(\eta_{\text {base }}+\eta_{\text {peak }} 1_{\{t \in \text { peak }\}}\right)-l_{t}\right) S_{t}\right)
\end{aligned}
$$


where everything is known at time $\tau$ except of the price process $S_{t}$ and the load process $l_{t}$. Plugging (23) into (8) we are able to compute the new RAROC.

We assume that the future prices given by the market are fair and have no market price of risk, i.e. they reflect the average future spot prices. If we also assume that there are no transaction costs, especially no bid-ask spread, then we know that the expected value of the profit given by (23) will not change with the hedging strategy. Otherwise there would be an opportunity for arbitrage in the market.

Thus, the expected value of the profit distribution will not change but the quantile of the distribution will. The distribution will become denser and the quantile will lie much closer to the mean and thus, a trader will be able to reduce the risk. Unfortunately the liquidity of the future market is very limited what makes hedging for big positions in reality often difficult. As described

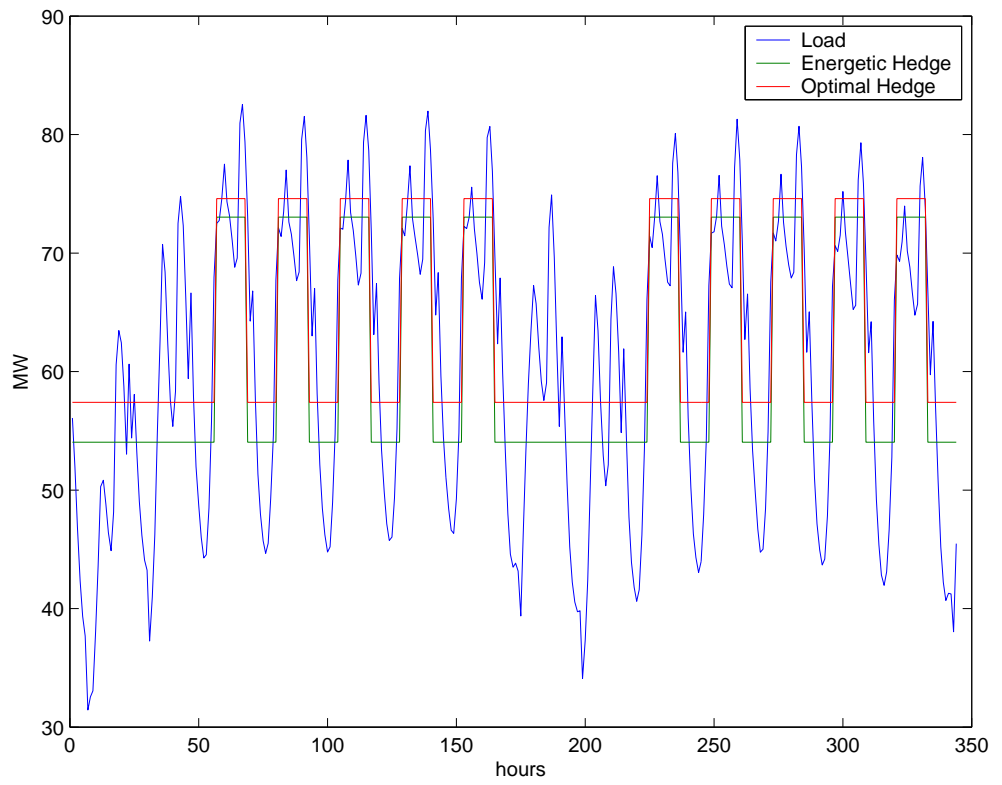

Fig. 3. Optimal Hedge for a typical customer load

before, the energetic hedge is the best strategy from an engineering point of view. But since the price is not constant this does not have to be the optimal strategy in the economic sense. If the maximization of the RAROC is our objective the optimization problem can be written as:

$$
\max _{\theta} F=\frac{\mathbb{E}[\text { Profit }]}{\mathbb{E}[\text { Profit }]-q_{\alpha}[\text { Profit }]}
$$

where $\theta$ stands for the hedging strategy $\left(\theta_{\text {peak }}, \theta_{\text {base }}\right)$. $\theta_{\text {peak }}$ and $\theta_{\text {base }}$ are the number of Peakload and Baseload future contracts to be bought or sold.

This problem cannot be solved with a closed formula but only with a Monte Carlo Simulation based approach described in the last section. 
Having developed a model for an Energy-RAROC in the next section we will derive formulas for risk premiums of full load electricity contracts.

\section{Risk Premiums of Full Load Contracts}

A full load contract with a customer leaves a trader with different types of risks. As compensation for taking over these risks he demands premiums in addition to the basic price.

In the following we will calculate the 'fair' overall price for the customer by the sum of the basic price and three risk premiums: a risk premium for the hourly spot market price risk, a premium for the volume risk and finally, a risk premium due to the price-volume correlation. To calculate an adequate price for the risk we will first explain what types of risks are covered by each of the premiums. Then we will show how the framework developed in the previous section can be used to compute these premiums.

\subsection{Market Price Risk}

The market price risk has its source in the volatile spot market. When entering a delivery contract, we do not know the future spot prices, but we decide about the retail price on the signing day. That means we accept to bear the risk of hourly changing market prices on behalf of the customer. As we saw in the previous section, a fraction of the risk can be hedged by future contracts. But since only baseload and peakload contracts for months, quarters and years are available and the customer load curve changes hourly, a part of the risk still remains. Thus, for taking the remaining market price risk the trader should be paid an adequate risk premium.

To determine the market premium, we will use the same setting as in the first part of the previous section: A deterministic load curve $\hat{l}_{t}$ and a stochastic spot price process $S_{t}$. Here the price process is the only source of uncertainty. We will calculate the risk premium as the difference between a fair retail price regarding the risky nature of the contract and the fair retail price neglecting this risk.

The "fair" retail price $K$ per MWh without considering the market price risk is the price of $K$ such that the expected value of the P\&L function becomes zero. We denote this "fair" price with $K_{1}$. It can be computed using (7): 


$$
\mathbb{E}[\text { Profit }]=0 \Leftrightarrow K_{1}=\frac{\sum_{t=\tau}^{T} B_{0}(t) \hat{l}_{t} \mathbb{E}\left[S_{t}\right]}{\sum_{t=\tau}^{T} B_{0}(t) \hat{l}_{t}}
$$

Now we will also take the market price risk into consideration. As stated before, a project is valuable for us, i.e. adds economic value, if its RAROC is higher than an internal hurdle rate. A RAROC below the hurdle rate would destroy economic value and thus, would not be desirable for the company. Using this RAROC-based approach we can calculate a retail price $K_{2}$ which results in a RAROC equal to our hurdle rate. If $\mu$ denotes the internal hurdle rate, we compute $K_{2}$ using the condition:

$$
R A R O C=\mu
$$

Plugging in (8) we get:

$$
\frac{K_{2} \sum_{t=\tau}^{T} B_{0}(t) \hat{l}_{t}-\sum_{t=\tau}^{T} B_{0}(t) \mathbb{E}\left[S_{t}\right] \hat{l}_{t}}{K_{2} \sum_{t=\tau}^{T} B_{0}(t) \hat{l}_{t}-\sum_{t=\tau}^{T} B_{0}(t) \mathbb{E}\left[S_{t}\right] \hat{l}_{t}-q_{\alpha}\left[K_{2} \sum_{t=\tau}^{T} B_{0}(t) \hat{l}_{t}-\sum_{t=\tau}^{T} B_{0}(t) S_{t} \hat{l}_{t}\right]}=\mu
$$

Solving for $K_{2}$, this leads to:

$$
K_{2}=\frac{\mu\left(q_{1-\alpha}\left[\sum_{t=\tau}^{T} B_{0}(t) S_{t} \hat{l}_{t}\right]-\sum_{t=\tau}^{T} B_{0}(t) \hat{l}_{t} \mathbb{E}\left[S_{t}\right]\right)+\sum_{t=\tau}^{T} B_{0}(t) \hat{l}_{t} \mathbb{E}\left[S_{t}\right]}{\sum_{t=\tau}^{T} B_{0}(t) \hat{l}_{t}}
$$

The value $K_{2}$ gives us the fair price if we require the internal hurdle rate $\mu$. Thus, we can determine the premium we want to receive per MWh due to our exposure to spot market price risk $p_{m}$ as:

$$
p_{m}=K_{2}-K_{1}=\frac{\mu\left(q_{1-\alpha}\left[\sum_{t=\tau}^{T} B_{0}(t) S_{t} \hat{l}_{t}\right]-\sum_{t=\tau}^{T} B_{0}(t) \hat{l}_{t} \mathbb{E}\left[S_{t}\right]\right)}{\sum_{t=\tau}^{T} B_{0}(t) \hat{l}_{t}}
$$

Note that this exactly the Economic Capital multiplied by $\mu$ and divided by the total amount of energy. This is not surprising since we demand as premium the return of $\mu$ on the capital we need to put aside due to the risky nature of the deal. Dividing by the total amount of energy just standardize the total premium for the contract to the premium per MWh so that we are able to compare contracts with different amounts of energy. 


\subsection{Volume Risk}

When entering a full load contract the trader does not only take over the market price risk, but also the volume risk, since the customer is allowed to use an arbitrary amount of energy. To determine the premium for this risk, we will use stochastic load curves. Again, we set the price $K_{3}$ as the price leading to a zero expected profit, i.e.:

$$
\mathbb{E}[\text { Profit }]=0 \Leftrightarrow K_{3}=\frac{\sum_{t=\tau}^{T} B_{0}(t) \mathbb{E}\left[S_{t} l_{t}\right]}{\sum_{t=\tau}^{T} B_{0}(t) \mathbb{E}\left[l_{t}\right]}
$$

$K_{3}$ is the fair price disregarding market price and volume risk. Taking these risks into consideration, we can determine a price $K_{4}$, leading to a RAROC equal to the hurdle rate, i.e. we require:

$$
\frac{K_{4} \sum_{t=\tau}^{T} B_{0}(t) \mathbb{E}\left[l_{t}\right]-\sum_{t=\tau}^{T} B_{0}(t) \mathbb{E}\left[S_{t} l_{t}\right]}{K_{4} \sum_{t=\tau}^{T} B_{0}(t) \mathbb{E}\left[l_{t}\right]-\sum_{t=\tau}^{T} B_{0}(t) \mathbb{E}\left[S_{t} l_{t}\right]-q_{\alpha}\left[K_{4} \sum_{t=\tau}^{T} B_{0}(t) l_{t}-\sum_{t=\tau}^{T} B_{0}(t) S_{t} l_{t}\right]}=\mu
$$

Unfortunately, this equation cannot be solved analytically for $K_{4}$, so we have to use numerical methods to compute a solution for $K_{4}$. Then we are able to determine the risk premium for the volume risk. The difference between $K_{4}$ and $K_{3}$ captures both, the volume as well as the market price risk. Subtracting the market risk premium we get the volume risk premium $p_{v}$ :

$$
p_{v}=K_{4}-K_{3}-p_{m}
$$

\subsection{Price-Volume Correlation Risk}

In a last step, we will evaluate the risk premium for the correlation of price and volume of the customer demand. Typical customers tend to have an increasing demand at times when prices are high. The reason for this is clear: Both processes are driven by the same underlying factor.

Of course also the opposite is possible. A customer could control his demand load such that it is lower than the average when the overall grid load is higher. 
However, given a full load contract with a fixed price, there is no reason for a customer for such anticyclical behavior.

The risk due to price-volume correlation can be calculated by comparing $K_{3}$ and $K_{1}$. If we evaluate the expected value in equation (30) we get:

$$
K_{3}=\frac{\sum_{t=\tau}^{T} B_{0}(t) \mathbb{E}\left[S_{t}\right] \mathbb{E}\left[l_{t}\right]+\sum_{t=\tau}^{T} B_{0}(t) \operatorname{Cov}\left(l_{t}, S_{t}\right)}{\sum_{t=\tau}^{T} B_{0}(t) \mathbb{E}\left[l_{t}\right]}
$$

Subtracting (25) we get the change in price due to the systematic correlation between the load $l_{t}$ and the spot price $S_{t}$. This is the risk premium $p_{c}$ :

$$
p_{c}=K_{3}-K_{1}=\frac{\sum_{t=\tau}^{T} B_{0}(t) \operatorname{Cov}\left(l_{t}, S_{t}\right)}{\sum_{t=\tau}^{T} B_{0}(t) \hat{l}_{t}}
$$

Using the same substitution as in (19) we get:

$$
p_{c}=\frac{\beta \sum_{t=\tau}^{T} B_{0}(t) \hat{l}_{t} \operatorname{Cov}\left(\tilde{L}_{t}, S_{t}\right)}{\sum_{t=\tau}^{T} B_{0}(t) \hat{l}_{t}}
$$

Note that the premium $p_{c}$ is different to the premiums $p_{m}$ and $p_{v}$. To compute $p_{c}$ we do not need the RAROC approach as risk measure like for the other two premiums. We just compare two average values using the deterministic and the stochastic load curves. Neither do we need the internal hurdle rate $\mu$ nor the quantile of the profit and loss distribution. Thus, even if we decide to calculate our premiums in a different framework, (34) will stay the same.

\subsection{Overview over the Risk Premiums}

In the previous sections we have shown how the three risk premiums for market price risk, volume risk and price-volume correlation risk can be computed. We want to summarize the results in the following overview. The entire risk premium $p_{R}$ is given by:

$$
p_{R}=p_{m}+p_{v}+p_{c}
$$

while the single premiums can be computed as: 


$$
\begin{aligned}
p_{m} & =K_{2}-K_{1} \\
p_{v} & =K_{4}-K_{3}-K_{2}+K_{1} \\
p_{c} & =K_{3}-K_{1}
\end{aligned}
$$

hence we get

$$
p_{R}=K_{4}-K_{1}
$$

The premium $p_{R}$ is the amount of money per load unit we should charge our customer additionally to our production costs and profit margins to compensate us for the risk we have taken with the obligation to deliver as much energy as the customer wants for a fixed price.

In the next section we will conduct an empirical analysis to determine risk premiums for full load contracts of a representative group of industry customers and different public utility companies.

\section{Empirical Analysis}

\subsection{Description of the Framework for the Data Analysis}

In this section we will use the developed RAROC framework to determine risk premiums for a data-set of full load contract customers ${ }^{5}$. In the previous section we illustrated that there are two parameters to decide on that will have substantial impact on the risk premiums of a customer's contract: The value of $\alpha$ we use to compute the Cash Flow at Risk and the internal hurdle rate $\mu$ the electricity company wants to achieve. The first reflects our level of risk aversion, while the latter sets the return rate the shareholders require. In our empirical analysis we choose the confidence level as $\alpha=5 \%$ and the internal hurdle rate $\mu=20 \%$ for the calculations. Furthermore we assume a constant discounting rate of $5 \%$ per annum. The premiums are calculated based on the energetic hedge strategy described in section 3. For the necessary spot price and grid load simulations we use the three factor model SMaPS by Burger et al. (2004).

Customer load data with hourly resolution was available from the year January 1, 2000 until December 31, 2002. Based on these three years of load history

$\overline{5}$ This data-set was made available to us by EnBW Trading GmbH 
the costumers' betas are estimated and load simulations are generated. We choose the year 2005 as basis of our analysis. Thus, spot price simulations are adjusted to observed future quotes at the EEX for the 2005 on the 30 th of January 2004.

To obtain further information on the load curves, we also compute the following characteristics for the load curves of the customers:

The total annually energy:

$$
E=\sum_{t=\tau}^{T} l_{t}
$$

The maximum hourly power:

$$
P_{\max }=\max _{t}\left(l_{t}\right)
$$

The peak rate:

$$
\lambda_{\text {peak }}=\frac{\sum_{t=\tau}^{T} l_{t} 1_{\{t \in \text { peak }\}}}{\sum_{t=\tau}^{T} l_{t}}
$$

The off-peak rate:

$$
\lambda_{\text {offpeak }}=\frac{\sum_{t=\tau}^{T} l_{t} 1_{\{t \in \text { off-peak }\}}}{\sum_{t=\tau}^{T} l_{t}}
$$

The Full-Load Usage Hour Number:

$$
U=\frac{E}{P_{\max }}
$$

$E$ is simply the total energy consumed by a costumer over the considered time period while $P_{\max }$ is the maximum consumption in one hour. The peak rate $\lambda_{\text {peak }}$ and off-peak rate $\lambda_{\text {offpeak }}$ denote the fraction of energy that is consumed in the peak and off-peak hours, respectively. The Full-Load Usage Hour Number $U$ is a measure of how similar the load curve is to a Baseload Profile. For a one-year Baseload contract where in every hour of the whole year the same amount of energy $(1 \mathrm{MW})$ is consumed $U$ equals $8760 \mathrm{~h}$. For a peakload contract including the delivery of $1 \mathrm{MW}$ from 8:00am to 8:00pm, Mo.-Fr., $U$ equals $3120 \mathrm{~h}$. These figures are commonly used in the electricity business to describe a customer's load profile. Determined risk premiums will also be investigated with respect to load profile figures. 


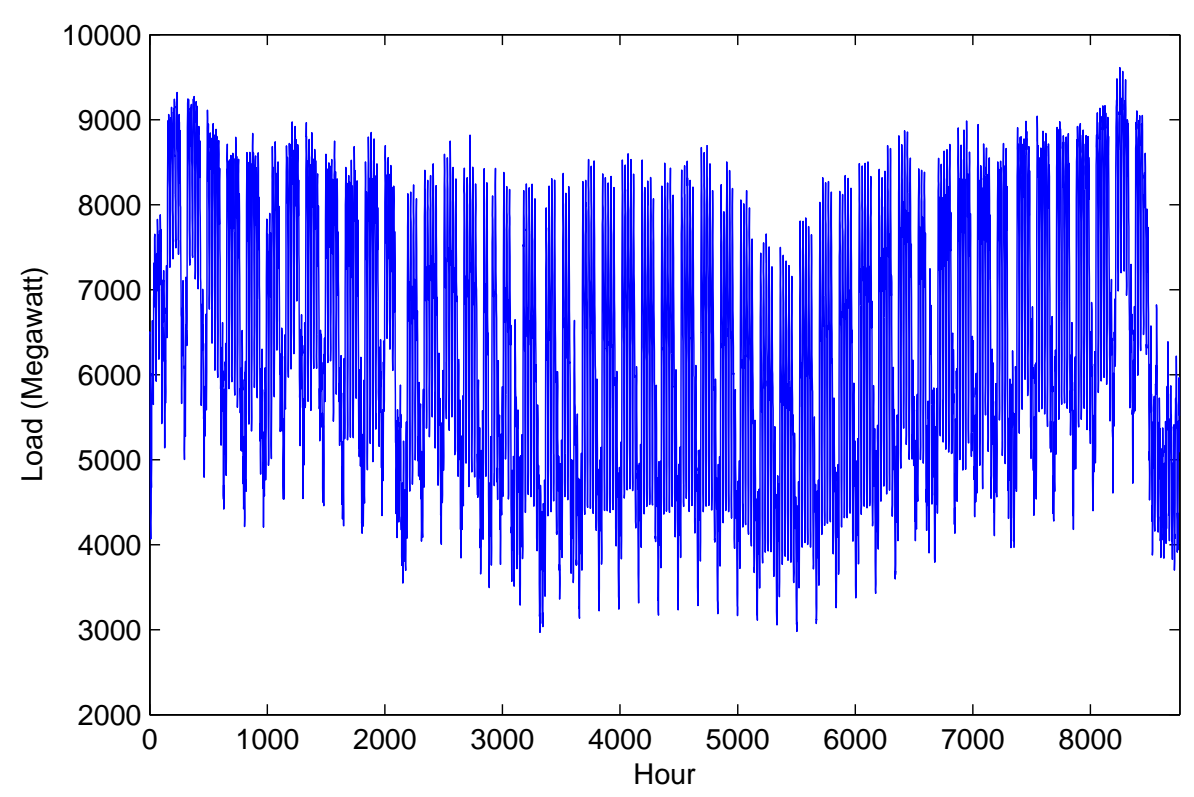

Fig. 4. Grid Load 2002 in hourly resolution

Table 1

\begin{tabular}{l|l}
\hline Parameter & Value \\
\hline \hline$E$ & $54,914,000 \mathrm{MWh}$ \\
\hline$P_{\max }$ & $9046 \mathrm{MW}$ \\
\hline$\lambda_{\text {peak }}$ & $43 \%$ \\
\hline$\lambda_{\text {offpeak }}$ & $57 \%$ \\
\hline$U$ & $6071 \mathrm{~h}$ \\
\hline
\end{tabular}

Figures $E, P_{\text {max }}, \lambda_{\text {peak }}, \lambda_{\text {offpeak }}$ and $U$ for the entire grid load in 2002.

\subsection{Risk Premiums for the entire Grid Load}

At first we want to analyze the entire grid load we use as risk factor for estimating the betas as described in section 3. Figure 4 shows the load (in Megawatt) for the year 2002 in hourly resolution. Table 1 summarizes the characteristic parameters of the grid load we defined above.

Applying our simulation model to the grid load we get a beta of 1 , since the deviation in the grid load itself was our systematic risk factor. To calculate the risk premiums $p_{c}, p_{m}, p_{v}$ and the entire risk premium $p_{R}$ we first determine the 'fair prices' $K_{1}-K_{4}$ and then use equations (36), (37) and (38) to obtain the corresponding risk premiums. Table 2 shows the results for the determined risk premiums for the entire grid load.

Thus, based on the chosen confidence level $\alpha=5 \%$, hurdle rate $\mu=20 \%$ and 
Table 2

\begin{tabular}{l|l}
\hline$p_{c}$ & 24.43 \\
\hline$p_{m}$ & 7.13 \\
\hline$p_{v}$ & 1.77 \\
\hline$p_{R}$ & 33.33 \\
\hline
\end{tabular}

Risk Premiums for the Grid Load (in Cent/MWh)

assumed discounting rate of $5 \%$ per annum a total risk premium of 33.33 Cent per MWh is required if we commit ourself to the delivery of the entire grid load under full load contract delivery terms.

\subsection{Analysis of the Data Set}

In this section we analyze a data set of $n=102$ wholesale customers for which we had historical loadcurves in hourly resolution available for the years 2000, 2001 and 2002. For each company $i=1, . ., 102$ we determine the value of beta, estimate a load curve for 2005 and generate stochastic simulations based on the grid load process. Then the risk premiums $p_{c}, p_{m}$ and $p_{v}$ are calculated. Additionally, we compute the characteristic load figures $E, P_{\text {max }}, \lambda_{\text {peak }}, \lambda_{\text {of fpeak }}$ and $U$ for each customer.

Figure 5 shows the histograms of the market price risk $p_{m}$, volume risk $p_{v}$, price-volume correlation risk $p_{c}$ and the total risk premium $p_{R}$. We find that the distributions of the different risk premiums are skewed to the right.

While for many customers, the price-volume correlation $p_{c}$ represents the biggest part of the entire risk premium $p_{R}$, the magnitude of the volume risk premium $p_{v}$ is compared to $p_{m}$ and $p_{c}$ very small. This makes intuitively sense, since $p_{v}$ captures only the systematic risk related to changes in the overall quantity of a customer's load over the entire year and not the daily fluctuations. This risk is very low for a typical wholesale customer compared to the price risk.

For a few customers we obtain negative risk premiums $p_{c}$ indicating negative correlation with the market. When market demand and prices are high, these customers tend to have a load demand less then average.

The market price risk premium $p_{m}$ can be regarded as a measure of hedgeability of a load curve. If it is possible to make a perfect hedge, the risk related to the market prices is zero. Since the Full-Load Usage Hour Number $U$ is a measure of how similar the load curve is to a Baseload Profile it also reflects the hedge-ability of a contract with the customer. Therefore, we expect a dependence structure between these two variables. Figure 6 shows a plot of 

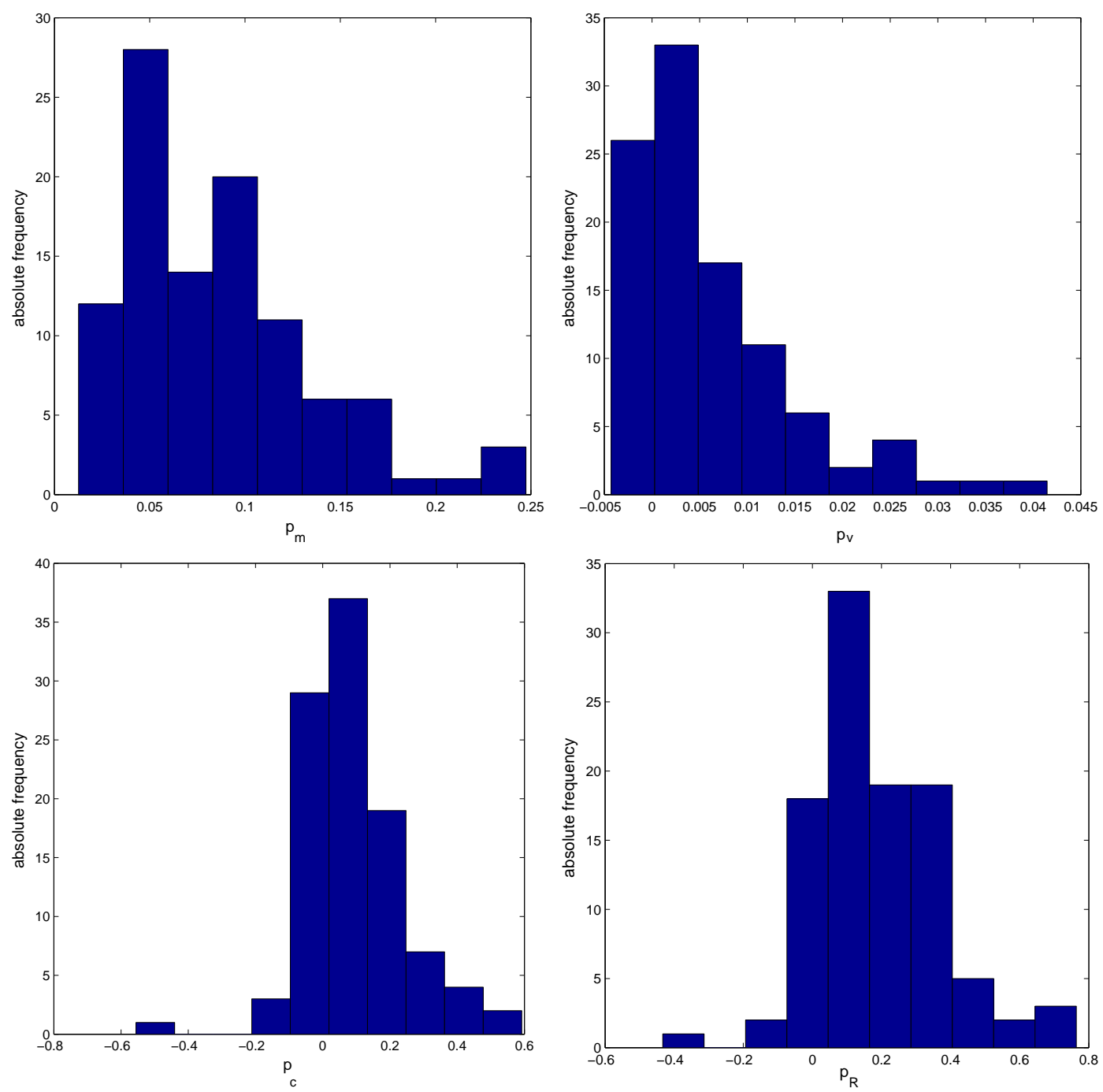

Fig. 5. Histogramm of the Risk Premiums (in Euro)

$p_{m}$ against $U$ where the negative correlation between the two figures becomes obvious. Hence knowing $U$ we are able to give a relatively precise estimation of $p_{m}$.

We also plot the price-volume correlation risk $p_{c}$ against the market risk $p_{m}$ to see whether there is a correlation between the two main risk premiums. The plot is shown in figure 7 .

We find that there is also a dependency between $p_{c}$ and $p_{m}$ such that for customers with higher market risk premiums also the price-volume correlation risk increases. The coefficient of correlation gives $\varrho_{p_{c}, p_{m}}=0.45$ indicating a moderate linear dependence structure.

After having analyzed the grid load and industry customers who have direct contracts with an electricity company, we want to calculate risk premiums 


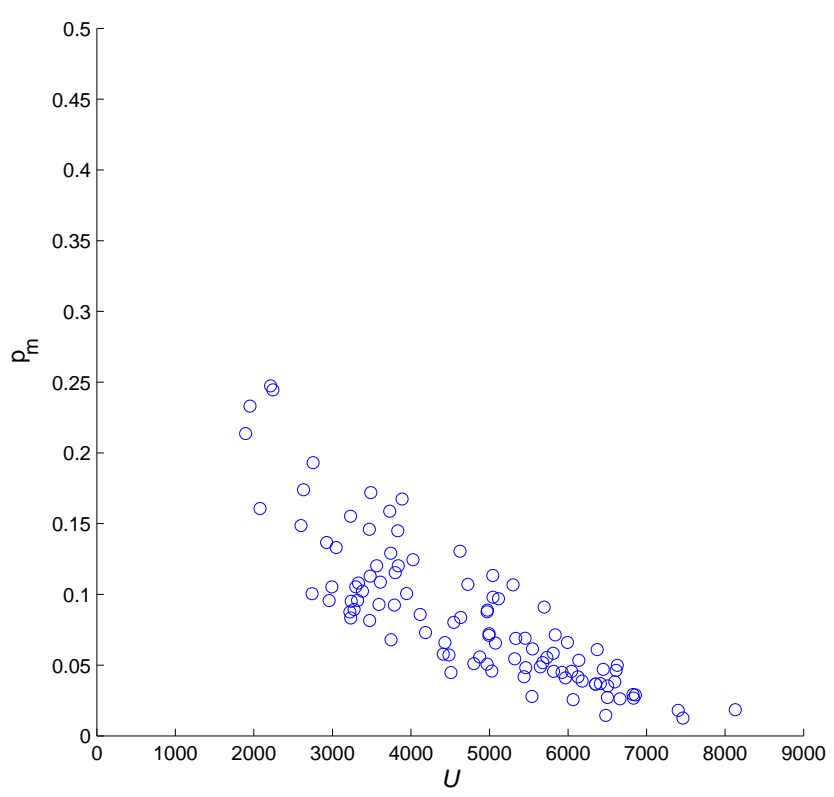

Fig. 6. $p_{m}$ plotted against $U$

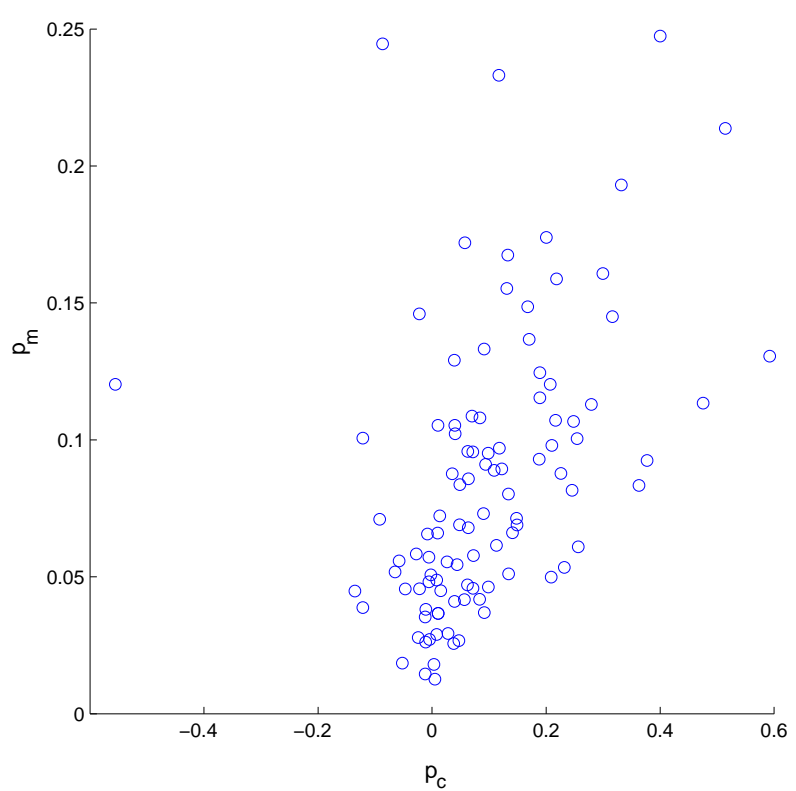

Fig. 7. $p_{c}$ plotted against $p_{m}$

for local public utility companies (PUC). These customers buy the electricity from an energy producer and sell it to private households and smaller industry customers who do not have a contract directly with the electricity producer.

For five public utility customers we carried out the same calculation as we have done for the industry customers before. Table 3 summarizes the results of our calculations. 


\begin{tabular}{|c|c|c|c|c|c|c|c|c|c|}
\hline No. & $p_{c}$ & $p_{m}$ & $p_{v}$ & $p_{R}$ & $\mathrm{E}[\mathrm{MWh}]$ & $P_{\max }[M W]$ & $\lambda_{\text {peak }}$ & $\lambda_{\text {offpeak }}$ & $U$ \\
\hline \hline PUC 1 & 31.06 & 8.17 & 3.00 & 42.23 & 139200 & 24.7 & 0.46 & 0.54 & 5642 \\
\hline PUC 2 & 21.99 & 6.98 & 1.46 & 30.43 & 217310 & 38.3 & 0.45 & 0.55 & 5677 \\
\hline PUC 3 & 9.60 & 6.28 & 0.74 & 16.62 & 864760 & 14.9 & 0.46 & 0.54 & 5788 \\
\hline PUC 4 & 25.50 & 6.93 & 2.38 & 34.67 & 1703800 & 279.0 & 0.44 & 0.56 & 6105 \\
\hline PUC 5 & 22.91 & 8.84 & 1.46 & 32.82 & 180130 & 34.2 & 0.48 & 0.52 & 5268 \\
\hline
\end{tabular}

Table 3

Results of the PUC (Premiums in Cent/MWh)

Considering the calculated risk premiums we find that for the considered PUCs the main source of risk is the price-volume correlation risk $p_{c}$. It accounts for approximately $70 \%$ of the total calculated premiums. Again the determined risk premiums for $p_{v}$ is by far the smallest. Further we obtain big differences in the magnitude of the risk premiums. PUC 1 has a overall premium which is three times higher than the premium of PUC 3. This is mainly due to a very low price-volume correlation risk of PUC 3. At a first glance PUC 2, PUC 4 and PUC 5 seem to provide very similar results. However, taking a closer look we observe that PUC 4 has a comparatively high volume risk, whereas the market price risk of PUC 5 is the highest among all public utility companies. We conclude that also among public utility companies there exist significant differences in load curves that from a RAROC perspective should lead to quite different assigned risk premiums.

\section{Conclusions}

The deregulation process of electricity markets has forced energy providers to react to the new situation. Due to the abolishment of monopolies and the launch of open markets, prices have to be calculated closer to profit frontiers to remain competitive. This entails an efficient risk management to ensure the financial survival of the energy provider even in case of bad market scenarios.

Considering wholesale electricity markets our paper provided a new methodology for quantifying the risk of so-called full load or wholesale electricity contracts. These contracts can be considered as accounting for an essential fraction of the electricity an energy provider is selling. Using a RAROC framework we were able to evaluate electricity contracts and to calculate risk premiums the supplier should charge customers for the risks related to them. Our approach does not consider the risk of market price fluctuations only but also includes consumption volume risk and price-volume correlation effects between the spot market prices and the customers' load curves. 
In an empirical study on whole sale contracts for industry customers and public utility companies of a German energy provider we illustrated the usefulness of the approach. Our findings were quite different risk premiums for the considered customers being based on their load curve profile. Our second main result was the importance of considering also price-volume correlation effects when determining premiums for electricity whole sale contracts.

We point out that so far model risk, operational risk or risks related to reserve energy were not considered in our evaluation scheme. Further, CFaR and as a consequence also the RAROC framework, though well-established in the industry, have been subject to various criticism (Artzner et al., 1999). Also the scope of our empirical analysis is limited to the EEX and caution should be exercised in generalizing the results also to other markets. Longstaff and Wang (2004) point out the individual structure of power markets while Mugele et al. (2005) obtain very diverse results considering electricity spot prices from different European power markets.

Therefore, for future work we propose to include also additional sources of risk and consider different models for simulating electricty spot prices and load curves. Further it might be appropriate to use another risk measure instead of CFaR, e.g. Expected Tail Loss. Finally, to obtain more general results, we recommend to test the framework in other energy markets as well.

\section{References}

Artzner, P., Delbaen, F., Eber, J.-M., Heath, D., 1999. Coherent Measure of Risk. Mathematical Finance 3 (9), 203-228.

Burger, M., Klar, B., Müller, A., Schindlmayr, G., 2004. A spot market model for pricing derivatives in electricity markets. Quantitative Finance 4, 109122.

Clewlow, L., Strickland, C., 2000. Energy Derivatives: Pricing and Risk Management. Lacima Publications.

Dowd, K., 1998. Beyond Value at Risk. Wiley.

EIA, 1999. Electric Power Monthly. Energy Information Administration, U.S. Department of Energy, August.

Froot, K., Stein, J., 1998. Risk management, capital budgeting, and capital structure policy for financial institutions: an integrated approach. Journal of Financial Economics 47, 55-82.

Galai, D., Masulis, R., 1976. The Option Pricing Model and the Risk Factor of Stock. Journal of Financial Economics 3, 53-81.

Jensen, M., 1968. The Performance of Mutual Funds in the Period 1945-1964. Journal of Finance 23, 389-416.

Jorion, P., 2001. Value at Risk. Vol. 2. McGraw-Hill.

Kaminski, V. (Ed.), 1999. Managing Energy Price Risk. Risk Books, London. 
Lehar, A., Welt, F., Wiesmayr, C., Zechner, J., 1998. Risikoadjustierte Performancemessung in Banken: Konzepte zur Risiko-Ertragssteuerung (Teil 1). Österreichisches Bankarchiv 46 (11), 857-862.

Longstaff, F., Wang, A., 2004. Electricity forward prices: A high-frequency empirical analysis. Journal of Finance 59, 1877-1900.

Lucia, J. J., Schwartz, E., 2002. Electricity prices and power derivatives: Evidence from the Nordic power exchange. Review of Derivatives Research 5, $5-50$.

Mugele, C., Rachev, S., Trück, S., 2005. Stable modeling of different European power markets. Investment Management and Financial Innovations 3.

Pilipovic, D., 1997. Energy Risk: Valuing and Managing Energy Derivatives. McGraw-Hill.

Punjabi, S., 1998. Many happy returns. Risk June, 71-76.

Punjabi, S., Dunsche, O., 1998. Effective risk-adjusted performance measurement for greater shareholder value. Journal of Lending and Credit Risk Management 81 (2), 18-24.

Sharpe, W., 1966. Mutual Fund Performance. Journal of Business 39, 119-138.

Treynor, J., 1965. How to Rate Management of Investment Funds. Harvard Business Review 43, 63-75.

Weron, R., 2000. Energy price risk management. Physica A 285, 127-134.

Zaik, E., Walter, J., Kelling, G., James, C., 1996. Raroc at the Bank of America: From Theory to Practice. Journal of Applied Corporate Finance 9 (2), $83-93$. 